Toward a Conceptual Framework for Scholarly Information Seeking

\author{
Sarah Rose Fitzgerald \\ University of Massachusetts, Amherst \\ W.E.B. Dubois Library \\ 154 Hicks Way \\ Amherst, MA 01003 \\ $\underline{\text { sfitzgerald@umass.edu }}$ \\ 413-577-3407
}

Conflicts of interest: none 


\title{
Toward a Conceptual Framework for Scholarly Information Seeking
}

Keywords: literature review, information seeking, university faculty, research universities

\begin{abstract}
This article reviews literature on information seeking theories and discusses the relevance of those theories to the information seeking habits of faculty with research expectations. A new model is constructed to depict the factors influencing scholarly information needs. The model incorporates career advancement factors, the influence of discovery tools, and the influence of interpersonal networks. Theoretical frameworks from T.D. Wilson and James Krikelas play important roles in building the model to describe scholarly information needs. This model can be of use to librarians, discovery tool designers, and university administrators supporting the information seeking, research, and teaching of faculty.
\end{abstract}

\section{Introduction}

This article discusses theories that help to explain the information seeking practices of scholars. Because scholars constitute the heaviest users of information, their specific information needs are important to understand. Ellis's (1989) work identifying six common information seeking behaviors of social science scholars is frequently used to understand scholarly information seeking. While Ellis' work provided an excellent description of how scholars seek information, it does not model the factors which lead to information seeking choices. To fully understand information seeking in a population, it is important to understand both the question of "how" and the question of "why." A more robust understanding can lead to better service for patrons. In this article, I concentrate on motivations rather than behaviors like Wilson (1981), who created a framework to describe the motivations which lead to information seeking. Unlike Wilson's work, my framework focuses on scholars, who have particular information needs driven by the nature of their work. A new model to describe faculty information needs is needed because their needs are different and more specific than those of general users. Academic librarians serving faculty who create knowledge have a different mission than public librarians serving general patrons or librarians serving students focused on consuming existing knowledge. Academic librarians can benefit from a model tailored specifically to their patrons' needs. Though the information seeking theories this article builds upon arose from the study of a variety of populations, they have implications for the way scholars interact with information. This article divides the theoretical perspectives into three categories: those having to do with personal and career needs, those having to do with interpersonal factors and affect, and those having to do with the technological environment for information seeking.

\section{Review of Information Seeking Theories}

\section{Information Needs}

Personal, Career, and Environmental Needs

Wilson's (1981) model of information behavior begins with an information user's need. The user seeks information from formal systems designed for information seeking and informal systems 
not designed for information seeking, and meets with either success or failure at fulfilling their information need. If they succeed, they put the information to use. If they fail fully or partially, then they must return to the search process. Wilson's model includes barriers to the information seeking process. It shows that information needs arise from physiological, cognitive, and affective needs. These may be personal needs, needs arising from an individual's social role, or needs arising from their career environment. More recently, Savolainen (2016) has further articulated variables in Wilson's model to include types of affective and cognitive barriers which affect the information seeking process. Types of affective barriers include fear of unwanted information, shame of admitting ignorance, and dread of using information discovery systems. Types of cognitive variables include lack of communications skills, unawareness of information seeking tools, and poor search skills (Savolainen, 2015).

The information needs of faculty members arise from the need to improve practice of their field, personal inclinations, and the need to publish to sustain their careers. These needs may not always align. For example, the citations that might increase the likelihood of acceptance by a publication (such as to authors on the editorial board) may not be the publications most necessary to the argument the paper advances. Some scholars consider citations from journals behind paywalls more reliable than citations of open access materials. Topics may be driven less by need in the field than likelihood for publication, ease of data collection, or funding opportunities. Participant selection may be driven by convenience of access rather than appropriateness to a research question. The selection of data sets may be driven by what is already available rather than what is most useful. The information needs of faculty members are also affected by their needs for personal time. They have interests and demands outside of academia that limit the amount of time they can spend searching for and reading literature. They also have duties other than research in their careers, including teaching and service. Wolff, Rod, and Schonfeld (2016) found that 52\% of the scholars they surveyed agreed with the statement "I shape my research outputs and publication choices to match the criteria I perceive for success in tenure and promotion processes" (p.30).

Wilson's (1997) updated model of information behavior replaced the idea of barriers with intervening variables, recognizing that sometimes factors encountered during a search serve to support information seeking, not just hinder it. Intervening variables in his updated model include psychological variables, demographic variables, interpersonal variables, environmental variables, and source characteristics. Some examples of specific intervening factors include budget constraints, time constraints, and cultural norms. For scholars, intervening factors might include the approach of deadlines (such as conference submission deadlines or the approach of tenure review), getting to know a new colleague who has ideas on your line of research, pursuing a particular grant, or the introduction of a new professional organization or publication in your area. Wilson's model shows that users may be involved in passive attention (such as listening to news without a specific information goal), passive search (encountering relevant information in the course of another search), active searching, or ongoing searching. In today's information environment, passive attention to scholarship can take place on social media sites. Scholars can follow one another's updates or follow a particular topic on sites like Twitter, Facebook, Academia.edu, Research Gate, or through RSS feeds (Chapman \& Greenhow, 2019). Wilson's 
model also includes the ideas of risk and reward (searching decreases when the gains from more searching decrease). Risks and benefits of information seeking include economic, physical, social, and emotional risks and rewards.

\section{Prior Knowledge}

Brenda Dervin emphasizes that users' information seeking is affected by the situation they are in at the time of the search. Dervin's (1998) theory of sense-making states that information seeking behavior is internal as well as external. Users' information needs depend on their prior knowledge and current situation. When they encounter a gap in their knowledge, they attempt to bridge it through information gathering and interpretation. The sense they make out of a topic depends on the way they approach the topic. Dervin's theory emphasizes the importance of the context of time and space in information seeking. Her emphasis on the transitory nature of information seeking contexts is frequently referenced in scholarship employing information seeking theory, often to improve other information seeking theories such as those proposed by Chatman (Savolainen, 2009). An individual may approach a topic differently in a variety of situations or at different points in their lives. The personal and career needs of users change over time and the events going on in their lives and in their field focus their attention differently throughout their careers. For scholars, this means their information seeking looks different at the beginning of their careers, during their development as doctoral students and their work as an assistant professor, than their work later in their careers, once they have achieved tenure. The scholarly body of literature in their field is full of gaps they are trying to bridge to progress their own knowledge and knowledge in their field.

\section{Orientation toward Help Seeking}

\section{Intrapersonal, interpersonal, and impersonal sources}

Krikelas (1983) wrote that users' first source of information is their own mind. Users bring their past experiences and creativity to problems. When this proves insufficient to solve a problem, users look for answers externally. First, they look to people near at hand, next they look to experts on the topic, and then they look to literature on the topic. Krikelas sees information seeking as inseparable from information giving. Helping colleagues can be an investment to foster helpful relationships for future research needs or develop a scholar's critical eye for examining their own work. Krikelas hypothesized that the reason people tend to bypass librarians when visiting the library, despite a general preference for interpersonal sources over impersonal sources, is that people associate the library with impersonal rather than interpersonal sources. However, scholars do not have the same preference as other users for seeking information from people before literature that Krikelas describes, since they are accustomed to spending a lot of time with literature and see literature as an extension of the scholars who compose it (Fitzgerald, 2018).

The way scholars interact with one another has been influenced by the digital age. Prior to the digital revolution, scholars spent more time in libraries and had more opportunity to make connections in libraries. Now libraries are less often gathering sites of academic communities at the faculty level, and academic communities have changed with the change in venue. Scholars 
meet yearly at disciplinary association meetings. They communicate or monitor one another online. The chance of a serendipitous encounter with a scholar from outside one's discipline or outside academia has decreased. This might help explain the recent increasing push for interdisciplinarity in academia. Increased calls for interdisciplinarity also lead scholars to gravitate toward general information search tools rather than discipline specific ones (Jamali \& Nicholas, 2010).

\section{Information avoidance}

Elfreda Chatman studied the emotional components of information seeking. Chatman (1996) puts forward the idea of insiders and outsiders to explain why individuals tend to trust others like themselves to understand them best. She advances the idea that social groups prefer to remain exclusive and thereby bar themselves from useful information that could be gained from other groups. Concealing needs is a way of not becoming burdensome, indebted, or responsible for reciprocating any help a colleague might provide. Sometimes avoidance of seeking help stems from the perception that those with the power to help do not care to help. Although avoiding help seeking is intended as an act of self-protection, it can have negative consequences. The information avoider may still appear weak in the eyes of their peers because they were not able to accomplish a task successfully and did not ask for help. Chatman also discusses the idea that help seeking may be avoided if it is not seen as a social norm. An individual may not ask for help from someone who can provide it because they do not see it as an appropriate request based on their relationship with the other person. In the scholarly environment, academic silos may create insiders and outsiders. Well-established scholars may feel embarrassed to ask for help from a scholar with less experience and vice versa. As a result, scholars may ask someone to do work for them rather than ask to be taught new skills. Critics of Chatman's work point out that it does not discuss the emotional toll that discriminatory experiences based on race, sexuality, and gender identity can have on people's orientation toward information seeking (Cooke, et al, 2019). Experiences with discrimination can discourage scholars from help seeking, particularly from those who belong to more privileged demographics.

Chatman (1990) applied alienation theory to information seeking. She argued that competition and mistrust can prevent people from talking about their information needs. She focused her research on impoverished populations, not scholars. However, Chatman points out that information poverty is not necessarily correlated with economic poverty. With this in mind, we can see that advanced scholars may also sometimes avoid asking for help. They may feel that as highly educated individuals they ought not to need help. They may ask for help indirectly so as not to appear ignorant. They might also feel that no one could help them because their topic is extremely specialized. They may avoid asking for help to protect their ideas before they have published them. In some fields, scholars have addressed this problem by posting their ideas online before they are formally published, in order to lay claim to ideas in writing before others do. Scholars from minority backgrounds who are becoming better included in academia and whom we must strive to retain may be particularly prone to information avoidance because they often feel like outsiders to academia (Settles, et al, 2019). 
Chatman (1991) argues that impoverished populations have limited social circles and therefore lack access to some information channels that would help them. She argues that impoverished populations seek immediate gratification, which limits the kind of help they seek. Scholars also have a limited social circle and incentives to seek certain types of information over others. Other scholars in the same field are the most likely interpersonal contacts for scholars to seek help from, because they are easily accessible and highly informed about the subject matter. These incentives to stay within the field are hurdles to contacting scholars outside the field who might be able to offer a different perspective. Huotaria \& Chatman (2001) have also used Chatman's theory of "small worlds" of information seeking to describe the behavior of organizations. University departments and scholarly disciplinary organizations have norms and values around what information is important, what questions should be asked, and how to look for the answers.

Potential benefits of seeking help from a fellow researcher on a research project include: access to data analysis software, access to a colleague's knowledge of a data analysis technique, access to funding sources, access to research participants or data sets, or access to policy makers or practitioners who might implement a study's findings. Seeking help from a practitioner or policy maker can provide insight into problems, access to funding, access to participants, or a greater impact for the research. There are also potential benefits from seeking help from a librarian. Researchers who have been working for a long time since their training may not be aware of all the options they have for information seeking. Researchers who were educated at a different institution or in a different country might also be unaware of some resources available to them at their current institution. It's also possible to learn about these resources from a fellow scholar.

\section{Tools for Information Seeking}

\section{The Influence of Tools}

I now move to a discussion of information seeking theory related to the technological environment. Lev Vygotsky, a Russian psychologist, wrote in the 1920s about the "activity theory" of learning. He argued that the tools used to access information users' relationship to that information (Nardi, 1996). He said that their plans and ideas as well as the artifacts and devices they use affect their learning. The language and symbols used for learning affect learning. Conventions and norms surrounding the systems they use also affect their information behavior. Vygotsky's theory is important to consider in the digital age, when many of the tools for information seeking have changed and continue to change. Vygotsky (1978) also introduced the idea of the zone of proximal development. This zone is the difference between a learner's capacity to learn independently and their capacity to learn with guidance. This can be an important concept when it comes to whether scholars learn a new concept from a colleague, or at a conference, or by reading independently. Wilson (2009) discusses the applications of Vygotsky's theory for information seeking activities.

The way a scholar searches impacts the results they get. A survey of researchers' e-journal use found that the ability to search by keywords expands the breadth of journals used by researchers by retrieving hits from titles they wouldn't otherwise use (Nicholas, Williams, Rowlands, \& Jamali, 2010). On the other hand, using keywords can limit the literature a scholar retrieves from 
a search by excluding synonyms, unless the scholar repeats the search using alternate terminology or makes use of controlled vocabulary systems that tie synonyms together. Controlled vocabulary can also be a good way to limit search results to exclude similarly named topics that are irrelevant. Using Google Scholar as a primary means to access information, can be problematic because it does not offer the subject heading search option provided by library databases.

The search engine a scholar uses affects the search results they receive. Some search engines personalize results based on past browsing history and others do not. Google Scholar partially bases the order of hits on the publication, number of citations, and the author of articles (Nentwich \& Konig, 2012). This is problematic because journal prestige and author prestige are not necessarily indicators of a quality article. Though it leads to prestigious citations that may sway reviewers and readers, it also perpetuates the Matthew effect (Merton, 1968), boosting popular articles at the expense of lesser-known articles. The language scholars use also affects the literature they find. Using a general search tool such as Google Scholar rather than a database targeting a specific field could lead to an increased use of citations to outside disciplines. When selecting a search tool, scholars may consider using tools and terms from their field so they will find citations that will be familiar to their reviewers and readers, as well as using broader tools which may provide sources from outside their own field.

Like Google Scholar, library databases also have limitations for access to scholarship. Many of them index only peer reviewed publications. While peer review is important to a scholar's tenure and promotion evaluations, it is not necessarily a good indicator of where the most relevant articles for a topic are to be found. Peer reviewed journals may publish only articles which adhere closely to established conventions while other sources may include more innovative work. Each database includes some publications and excludes others. Scholars should be aware of the choices they are making when they choose certain databases and not others. While the limiters in databases decrease the amount of information scholars must sift through by allowing them to select the age, disciplinary focus, or publication type of the literature they seek, limiters can also eliminate the serendipity of discovering literature from alternative disciplines and publication types. Serendipity can be useful in uncovering new connections and seeing from new perspectives.

\section{Diffusion Theory}

The tools scholars use for information seeking are influenced by how well information seeking tools have permeated their field. Rogers (2003) states that the rate at which innovations become popular over time among members of a given social system is dependent on: 1) the relative advantage of the innovation (prestige, convenience, cost, satisfaction), 2) its compatibility with the needs, values, and experiences of the users, 3) its complexity, 4) its "trialability", and 5) its observability and how visible its results are. Sometimes convenience outweighs thoroughness and sometimes additional needs require scholars to inconvenience themselves. Zoellner, K., Hines, S., Keenan, T. and Samson, S. (2015) found that faculty members tend to pass over physical books in favor of journal articles because of the convenience of accessing articles online through library databases. There is a danger that more relevant content is being passed over for 
the sake of convenience. Scholars may learn about search tools through one another, their students, the library's website, or librarians. How well acquainted a scholar is with an online tool may depend on how much exposure they have had to online environments. Rupp-Serrano and Robbins (2013) found that $37 \%$ of the education faculty they surveyed reported that lack of awareness of electronic resources was a barrier to their use of electronic library services.

\section{Principle of Least Effort}

Zipf's Principle of Least Effort is the idea that people will minimize the effort they expend to find information (Case, 2002). People will ask the person they are closest to or consult the source they are familiar with, rather than seek out the best source of information. They try to optimize the cost-benefit ratio of searching for literature. Zipf said that use of a source will be inversely proportional to its use rank. For example, the most frequently used source in a library will be used about twice as often as the second most frequently used source and three times as often as the third most frequently used source.

A similar phenomenon exists for the work of specific authors. This phenomenon is described by Lotka's Law, which states that the number of authors making X number of publications is about $1 / \mathrm{X}^{\mathrm{a}}$. This means the number of authors publishing few works is exponentially greater than the number of authors publishing a great number of works. This is related to the Matthew Effect described by Merton (1968) in which the works of well-known authors gain more use and citations through their notoriety and authors who are not well known continue to be overlooked. Well known authors also attract better funding and better credentialed assistants to help with their research. The Matthew Effect is named after the biblical passage from Matthew 25:29 which says "Unto every one that hath shall be given, and he shall have abundance, but from him that hath not shall be taken away even that which he hath."

The Matthew Effect applies to journals as well as authors. Bradford (1976) observed that the distribution of relevant articles among journals in a field can be described by the formula 1: $n: n^{2}$. For example, if 5 core journals contain about 200 articles relevant to a given topic, then to find another 200 relevant articles, one needs to look through 25 less relevant journals $\left(5^{2}\right)$. Examining additional journals provides diminishing returns. In the digital information environment, the number of sources to examine keeps growing. However, scholars are still only able to examine a limited amount of material. Rupp-Serrano and Robbins (2013) found that lack of time was a barrier to the use of electronic library services for $42 \%$ of the faculty they surveyed. This means that work in core outlets is read most and work in peripheral outlets is read only rarely. This can be problematic because peripheral work has the potential to bring new perspectives to a field.

While a wealth of resources can result in concentration on only a few, it can also result in superficial attention to a greater number of resources. Pirolli (2007) introduced Information Foraging Theory. This theory says that information users attempt to optimize the amount of knowledge gained through their interactions with information. It draws a comparison between the way animals hunt for food and the way humans search for information. The theory views humans as "informavores," a term introduced by George A. Miller. In the information foraging model, users rely on clues about how much information a source can give them. Pirolli names 
these clues the "information scent." When users are drawn in many directions by the scent of information (they know that many websites have useful information), they have less incentive to stay on one site. There is a risk in an information rich environment that scholars may spend less time with each of their sources.

The goal of scholarly information seeking is to advance knowledge. This results in particularly complex information seeking tasks. Bystrom and Jarvelin (1995) argue that as the complexity of a task increases, the complexity of the information needed for the task increases. They employed a combination of questionnaires about general habits and participant diaries about specific tasks to collect data for their study. They found that tasks that are more complex require several levels of information seeking. For more complex tasks, users first identify channels to help them find out how to find information for their tasks, and then they access those sources. For simpler tasks, users can simply access known sources for information. Tasks that are more complex also require more sources than simpler tasks. Simpler tasks more often result in successful searching. If scholars are to produce innovative knowledge, then they must seek innovative resources, which may entail using complex search techniques requiring considerable effort. This becomes an issue when combined with a ratcheting up of expectations for scholars including the increased pressure to publish, an exponentially growing body of scholarly literature to keep up with, the growing demands for peer review, and an expanding number of technologies to learn in pursuit of research and teaching trends.

\section{Model for Scholarly Information Seeking}

The theories outlined in this article lead to the conclusion that as scholars search for information, they face multiple cognitive and affective needs that evolve. These needs arise from previous knowledge, the values of academic disciplines, the desire for career advancement, and the possibilities to advance the scholar's field. Some scholars may find time to monitor the field for information that may be useful later, but the growing problem of information overload means that many scholars may be relying on searching and asking for help when their needs arise. Although an exhaustive investigation of the literature on a topic is the ideal, often the diminishing returns of more searching means that scholars must draw the line somewhere more manageable. Searching may also be limited by the search tools available, a scholar's knowledge of such tools, and their willingness to seek out help. Willingness to seek help is influenced by a scholar's level of self-confidence and their social network. A scholar's self-confidence regarding an information seeking task may stem from their knowledge of search tools, knowledge of the field, and past successes or failures. Confidence can determine how ambitious a scholar is and whether they seek out help. It could also determine whether they seek help in the form of asking to be taught a new skill, or help in the form of asking someone to perform a task on their behalf. Figure 1 depicts the factors from information behavior theory that influence the information seeking strategies of scholars. 


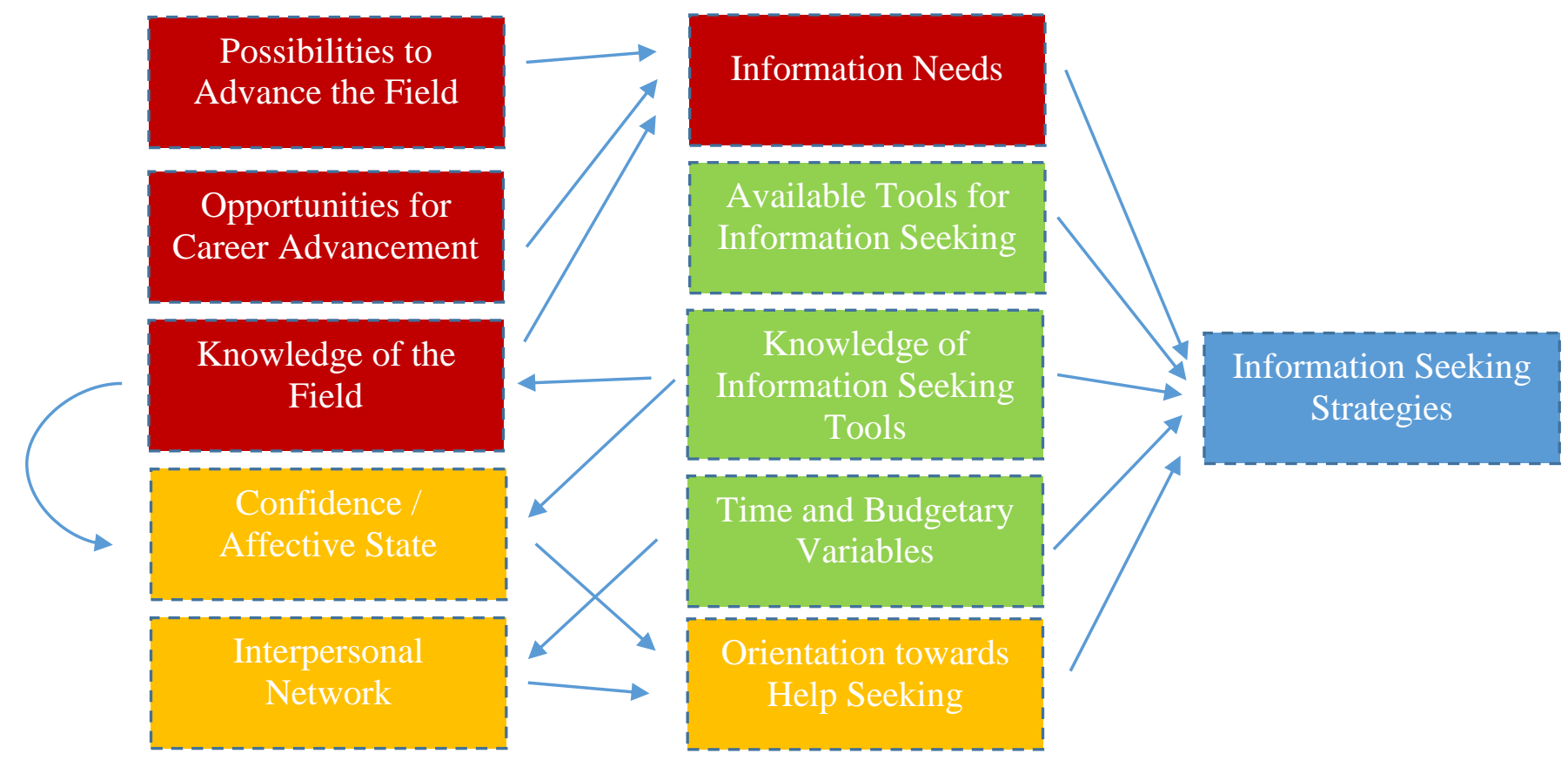

Figure 1. Factors that contribute to the information seeking strategies of scholars.

The figure above shows three sets factors that contribute to information seeking strategies, the influence of their field in terms of what work will be rewarded, the scholar's emotional orientation toward seeking help from others, and the tools available for information seeking. Factors in red relate to field influences on information seeking, factors in yellow relate to interpersonal and emotion influences, and factors in green relate to tools and resources for information seeking. Scholars of faculty work may find this model helpful as a guide in considering which opportunities, tools, and strategies for information seeking are likely to be adopted with enthusiasm by scholars.

Although the variables represented in the model appear distinct from one another, in the information seeking process, these concepts blur together and overlap. I have represented this using dashed rather than solid outlines for each shape. One's interpersonal network influences one's confidence, opportunities for career advancement, and knowledge of information discovery tools. One's time spent building knowledge of a discipline can eat into the time one can spend on building knowledge of discovery tools. Conversely, advanced knowledge of an information related discipline can enhance one's knowledge of available discovery tools. Increasing knowledge of one's discipline can improve one's confidence level as a scholar. Confidence can lead to more contacts and increased likelihood of funding for research.

"Possibilities to advance the field" is a concept dependent on time and efforts toward filling information gaps in the body of scholarly knowledge. As Dervin points out, information needs are dependent on time and context. For librarian-faculty engagement, this factor highlights the importance of being aware of research trends which may be driving research directions. "Knowledge of the field" is also related to partial knowledge on the individual rather than the 
field level. Scholars with training or experience in particular subfields, methods, and theoretical frameworks tend to build off of those bodies of knowledge, meaning that they may benefit from connections to related, but not identical ideas. Libraries can help facilitate this by seeking to connect scholars to resources and interpersonal relationships that are not entirely foreign, but also not repetitive of a department's current wheelhouse. "Opportunities for career advancement" relates to Wilson's concepts of diverging and converging sets of needs. Librarians seeking to support faculty information seeking can keep this concept in mind when designing programs for faculty development and inviting guest speakers. Some workshop topics lend themselves to impressing tenure and promotion committees and others may promote healthier work-life balance.

"Confidence/Affective State" is related to Chatman's idea of information avoidance. Scholars who have strong mentors as graduate students and junior faculty and form strong help networks will have more interpersonal resources to draw on for coauthor networks, career questions, and needs for emotional support. Librarians seeking to support faculty and future faculty can help foster these networks and relationships. This will bolster the resilience and tenacity of scholars facing challenges in their work. Special consideration may be given to scholars studying understudied topics and scholars at high pressure points in their careers who may face extra strain. Librarians can also encourage the spread of information about information discovery tools and methods through interpersonal relationships.

"Available tools for information seeking" and "Knowledge of information seeking tools" are variables which I added to the model in consideration of Vygotsky's theory of education. Librarians should keep scholars up to date with latest resources for information seeking in their field, and should educate scholars joining an institution about resources which may be new to them. Scholars incorporating new subfields or methods in their work may need additional guidance with tools they did not become familiar with in their previous research experiences. Finally, "Time and Budgetary Variables" appears in the model in accordance with Wilson's idea of time constraints and Zipf's idea of least effort. Librarians should consider demands on faculty time when planning opportunities for them to connect with new resources.

\section{Conclusion}

The implications of this model should be considered in the development and marketing of new tools for scholarly information seeking. Librarians should bear in mind the many demands on scholars' time and emotional state and the need for forming interpersonal connections when they plan outreach and engagement with faculty. It's especially important to consider the career demands and development needs of early career faculty who are working toward tenure. Teachers, faculty advisors, and librarians should consider this model of information seeking when preparing doctoral students for future faculty roles. Faculty members and administrators considering evaluation standards for tenure and promotion should take into account how the requirements they set will influence the motivation of faculty to choose research topics of value to the field, delegate research tasks appropriately to their research teams, and keep themselves thoroughly up to date with knowledge in their fields. The importance of career advancement in the model also speaks to the importance of tenure for faculty members to preserve their freedom 
to explore research questions which may only be possible to investigate with job security. Future research on this topic can verify the roles of the various factors for affective and cognitive information seeking variables in the population of research scholars. 


\section{References}

Bradford, S. C. (1976). Classic paper: Sources of information on specific subjects. Collection Management, 1(3-4), 95-104. https://doi.org/10.1300/J105v01n03_06

Byström, K., \& Järvelin, K. (1995). Task complexity affects information seeking and use. Information Processing and Management, 31(2), 191-213. https://doi.org/10.1016/0306$\underline{4573(95) 80035-\mathrm{R}}$

Case, D. O. (2002). Looking for information: A survey of research on information seeking, needs, and behavior. San Diego, CA: Academic Press.

Chapman, A. L., \& Greenhow, C. (2019). Citizen-Scholars: Social Media and the Changing Nature of Scholarship. 7(1), 11. MDPI AG. https://doi.org/10.3390/publications7010011

Chatman, E. A. (1990). Alienation theory: Application of a conceptual framework to a study of information among janitors. $R Q, 29(3)$. Retrieved from http://www.jstor.org/stable/25828550

Chatman, E. A. (1991). Life in a small world: Applicability of gratification theory to information-seeking behavior. Journal of the American Society for Information Science, 42(6), 438-449. https://doi.org/10.1002/(SICI)1097-4571(199107)42:6<438::AIDASI6>3.0.CO;2-B

Chatman, E. A. (1996). The impoverished life-world of outsiders. Journal of the American Society for Information Science, 47(3), 193-206. https://doi.org/10.1108/13673279810249369

Cooke, N. A., Miksa, S. D., Mehra, B., Gray, L. (2019). Chatman revisited: A panel reexamining and resituating social theories of identity, access, and marginalization in LIS. ALISE 2019 Conference Proceedings. Retrieved from http://hdl.handle.net/2142/105354

Dervin, B. (1998). Sense-making theory and practice: An overview of user interests in knowledge seeking and use. Journal of Knowledge Management, 2(2), 36-46. https://doi.org/10.1108/13673279810249369

Ellis, D. (1989). A behavioural model for information retrieval system design. Journal of Information Science, 15(4-5), 237-247. https://doi.org/10.1177/016555158901500406

Fitzgerald, S. R. (2018). The role of affect in the information seeking of productive scholars. The Journal of Academic Librarianship, 44 (2), 263-268. https://doi.org/10.1016/j.acalib.2018.01.001

Huotari, M., \& Chatman, E. (2001). Using everyday life information seeking to explain organizational behavior. Library \& Information Science Research, 23, 4, 351-366. https://doi.org/10.1016/S0740-8188(01)00093-7

Jamali, H. R., \& Nicholas, D. (2010). Interdisciplinarity and the information-seeking behavior of scientists. Information Processing \& Management, 46, (2), 233-243. https://doi.org/10.1016/j.ipm.2009.12.010 
Krikelas, J. (1983). Information-seeking behavior: Patterns and concepts. Drexel Library Quarterly, 19, 5-20.

Merton, R. (1968). Scientists and the "Matthew effect". New Society, 11, 277.

Nardi, B. A. (1996). Activity theory and human-computer interaction. In B. A. Nardi, Context and consciousness: Activity theory and human-computer interaction (pp.7-16). Cambridge, Mass: MIT Press.

Nentwich, M., \& Konig, R. (2012). Cyberscience 2.0: Research in the age of digital social networks. Frankfurt: Campus Verlag.

Nicholas, D., Williams, P., Rowlands, I., \& Jamali, H.R. (2010). Researchers' e-journal use and information seeking behavior. Journal of Information Science, 36 (4), 494-516. https://doi.org/10.1177/0165551510371883

Pirolli, P. (2007). Information foraging theory: Adaptive interaction with information. Cary, NC: Oxford University Press. Retrieved from http://www.ebrary.com

Rogers, E. M. (2003). Diffusion of innovations ( $5^{\text {th }}$ ed.) New York: Free Press.

Rupp-Serrano, K., \& Robbins, S. (2013). Information-Seeking Habits of Education Faculty. College \& Research Libraries, 74, 2, 131-142. https://doi.org/10.5860/crl-322

Savolainen, R. (2009). Small world and information grounds as contexts of information seeking and sharing. Library \& Information Science Research, 31 (1). 38-45. https://doi.org/10.1016/j.lisr.2008.10.007.

Savolainen, R. (2015). Cognitive barriers to information seeking: A conceptual analysis. Journal of Information Science, 41(5), 613-623. https://doi.org/10.1177/0165551515587850

Savolainen, R. (2016). Approaching the affective barriers to information seeking: the viewpoint of appraisal theory. Proceedings of ISIC: the information behaviour conference. 21 (4). http://informationr.net/ir/21-4/isic/isic1603.html

Settles, I.H, Buchanan, N.T., \& Dotson, K. (2019). Scrutinized but not recognized: (In)visibility and hypervisibility experiences of faculty of color. Journal of Vocational Behavior, 113, 62-74. https://doi.org/10.1016/j.jvb.2018.06.003

Vygotsky, L. S. (1978). Mind in society: The development of higher psychological processes. Cambridge, MA: Harvard University Press.

Wilson, T. D. (1981). On user studies and information needs. Journal of Documentation, 37(1), 3-15. https://doi.org/10.1108/eb026702

Wilson, T. D. (1997). Information behaviour: An interdisciplinary perspective. Information Processing \& Management, 33(4), 551-572. https://doi.org/10.1016/S0306$\underline{4573(97) 00028-9}$

Wilson, T.D. (2008), Activity theory and information seeking. Annual Review of Information Science and Technology, 42: 119-161. https://doi.org/10.1002/aris.2008.1440420111 
Wolff, C., Schonfeld, R. C., Rod, A. B., \& Ithaka S + R. (2016). Ithaka S+R US library survey 2015. Retrieved from http://www.sr.ithaka.org/wpcontent/uploads/2016/03/SR_Report_US_Faculty_Survey_2015040416.pdf

Zoellner, K., Hines, S., Keenan, T. \& Samson, S. (2015). Faculty research and publication practices. Portal: Libraries and the Academy 15(1), 111-131. http://doi.org/10.1353/pla.2015.0009 
Author Statement
\[ \text { Author Statement } \]

The author has no conflicts of interest to declare The author has no conflicts of interest to declare

(2)

